\title{
Worshipping the Tiger: Modeling Non-use Existence Values of Wildlife Spiritual Services
}

\author{
Adrian A. Lopes ${ }^{1} \cdot$ Shady S. Atallah ${ }^{2}$
}

Accepted: 20 March 2020 / Published online: 8 April 2020

(c) The Author(s) 2020

\begin{abstract}
Several indigenous tribes around the world derive spiritual value from revering fauna and flora species. Species conservation is not a prime objective of such traditions but can be an unintended consequence. Conventional species conservation practices ignore this spiritual value and tribes are often evicted from protected areas. We use the existence value framework to develop a coupled ecological-economic model of the use and non-use, existence values of wildlife for a tribe that derives spiritual value from a wildlife population. We calibrate the model for the Biligiri Rangaswamy Temple (BRT) Tiger Reserve in India with the resident Soligas tribe who consider tigers as sacred and back out an existence value of tigers in this reserve from a tribe manager's perspective. The model ascertains tiger population dynamics under several management scenarios. Steady-state convergence is observed under secure property rights for the Soligas. Scenarios in which they are evicted from the BRT reserve and lose their property rights yields localized tiger extinction. Finally, we generate a marginal existence value function and discuss the potential for using existence value estimates in guiding conservation policy.
\end{abstract}

Keywords Tiger $\cdot$ Public goods $\cdot$ Existence value $\cdot$ Conservation $\cdot$ Bioeconomic model

JEL Codes Q20 - Q51 - Q57 · C61

Lead authorship is shared between the two authors

Shady S. Atallah

Shadi.Atallah@unh.edu

Adrian A. Lopes

alopes@aus.edu

1 Department of Economics, American University of Sharjah, PO Box 26666,

University City, Sharjah, UAE

2 Department of Natural Resources and the Environment, Department of Economics, University of New Hampshire, 56 College Rd, Durham, NH 03824, USA 


\section{Introduction}

A fourth of animal and plant species are threatened with extinction (IUCN 2011) by direct threats such as overharvesting and indirect threats such as habitat loss and fragmentation (Ando and Langpap 2018). A similar share of carnivores is critically endangered, endangered, or vulnerable (Hilton-Taylor et al. 2009). Carnivores generate a variety of ecosystems services (ES): some of these are regulation ES whereby carnivores help stabilize ecosystems while others are provisioning (e.g., pelt) and cultural (e.g., recreation) ES. Some ES are derived through consumptive (e.g., trophy hunting) or non-consumptive use values (e.g., wildlife recreation). Others are derived through non-use values, such as existence values, and these are the least studied in part because they are the hardest to estimate. If nonuse existence values are significant relative to use values, then public resource management decisions based on benefit-cost analyses that omit these values are not socially optimal and might lead to extinction (Alexander 2000). In addition, many of the ES that provide nonuse values are public goods, and consequently, the conservation of the species providing them will be underprovided by private parties engaging in extractive use of the species, destruction of its habitat, or failing to maintain habitat health that is necessary for the survival of the species.

Conservation policies aimed at correcting the market failure in species conservation include habitat conservation programs, policies to encourage habitat ecosystem health maintenance, and management of hunting (Ando and Langpap 2018). One of the most common habitat conservation policies consists of establishing protected areas. When the species of conservation interest coexists with indigenous communities, the enforcement of the protected status of the area often involves the expulsion and exclusion of these communities. The practice is controversial on human rights and ethical grounds, and its effectiveness has been mixed (Dowie 2009; Lele et al. 2010). Here, we use an ecological-economic model to show that this practice will fail to maximize the net social value derived from the resource and can be counterproductive: When communities derive existence value from the species, such as the value gained from worshiping tigers by local tribes in southwestern India, their expulsion and exclusion lead to species extinction. In contrast, securing their property rights leads to species survival. We use a case study of an indigenous tribe that worships tigers and estimate the existence values the tribe derives from worshipping the tiger.

Conservationists have made claims that "tribal peoples are the best conservationists and guardians of the natural world" (Rust 2016). In some cases, such claims are supported by evidence. For example, the Soligas tribe in the Western Ghats of India reveres the wild Bengal tiger (Panthera tigris ssp. tigris) according to their customary spiritual beliefs. The NGO Survival International released data showing that the population of tigers in that region doubled between the years 2010 and 2014 and that the population growth rate was higher than the national average in India (Rust 2016). However, such claims and descriptive data might include confounding factors leading to this higher-than-average growth rate that might not be related to the co-existence of the species with the tribe. Moreover, there is no formal theoretical or empirical analysis in the conservation economics literature on the effect that existence values - which local populations derive from a species-have on the conservation status of that species. More generally, the literature on non-consumptive values in conservation tends to be limited to tourism use values (Skonhoft 1998). Although it is widely believed that non-consumptive public good values of endangered species may be considerable (Bulte and van Kooten 1999b) and may well be greater than consumptive 
values (Swanson and Barbier 1992), no estimates of such values exist. This is in part because non-market valuation may not be appropriate to estimate the resource values of indigenous peoples who have socio-political structures and decision-making processes that are inconsistent with the referendum format of valuation surveys used to generate welfare estimates (Adamowicz et al. 1998).

It is not surprising then that very few studies estimate existence values for endangered species as would be appropriate to do in the case of the spiritual values of the Bengal tiger. One notable exception is Zabel et al. (2011), a study that accounts for the existence values of tiger conservation in the case of co-existence with livestock. However, the existence values the authors consider represent values society at large might put on the knowledge that the species exists, which typically capture moral satisfaction, "warm glow" and ethical dimensions (Alpizar et al. 2003) but not spiritual values derived by the local populations from worshipping the tiger. Moreover, given the lack of functions that can be used to model such values, they focus on deriving a wide range of marginal existence values that guarantee interior solutions, as opposed to backing out existence value estimates as a function of population levels.

In this paper, we provide a case study of the Soligas tribe living in the Biligiri Rangaswamy Temple (BRT) Tiger Reserve located in India's Western Ghats. This tribe attaches significant spiritual value to the Bengal tiger. We estimate the existence values ${ }^{1}$ that lead to a higher population of tigers when the tribe's property rights are secured and show that exclusionary policies can lead to local species extinction. We develop a bioeconomic model that includes both extraction value and non-use existence value of the Bengal tiger. The model we propose includes a specification of an existence value function, which allows us to estimate the tribe's existence values derived from worshipping the tiger, as opposed to identifying a wide range of society's values as in Zabel et al. (2011). We compare conservation policies that consist of either keeping or taking away property rights from the tribe, with and without poaching fines. We find that, if taking away property rights from the tribe leads to myopic harvesting (e.g., Skonhoft and Solstad 1996), poaching increases as a result of insecure property rights, even in the presence of fines, which leads to localized tiger extinction. When the tribe's property rights are safeguarded, on the other hand, existence values are realized, and the species population increases.

The policy implications regarding property rights is a salient and current one because local courts can and have secured rights of indigenous communities to remain or return to their ancestral lands within a tiger reserve through enforcement of the 2006 Indian Forest Rights Act (Bhullar 2008). There has however been considerable uncertainty about the future implementation of land claims for forest-dwelling indigenous communities in India. In the past, several forest-dwelling tribespeople have seen their land claims rejected in the Supreme Court of India under the Forest Rights Act in circumstances where they lacked proof of possessing the land for the last three generations or more (Sengar 2019). Eviction from ancestral lands is an unpredictable threat that renders land title uncertain for many forest-dwelling tribes in India. In the Soligas case,

\footnotetext{
1 We use the term 'existence value' instead of 'spiritual value' because of the impossibility to separate the two. According to the Total Economic Value topology of values (Davidson 2013), existence value includes values derived from self-transcendence, cultural identity, heritage values and spiritual services. Because these values might not be separable, we use the term existence value more generally, even though the tribe worships the tiger and spiritual values are likely to be a major component of the existence values we estimate.
} 
Fanari (2019) describes how land rights to the BRT were taken away from them temporarily before reacquiring them in accordance with the Forest Rights Act.

The poaching of endangered species - such as tigers-attracts a penalty as per the Indian Wildlife Protection Act (MOEF 2013). As is the case with any other tribe, the Soligas are subject to this poaching penalty in accordance with the law. In our model, we numerically estimate the existence values the Soligas tribe derives from worshipping the tiger. The numerical analysis begins with a revealed preference estimation of an existence value weight using a model calibration that represents the current situation of the Soligas wherein they currently have land rights in the BRT and are subject to a poaching penalty. We then examine alternative policy scenarios in which property rights are either secured or not, with and without poaching fines, to account for the possibility of a change in the enforcement of land claims in the future. We discuss the possible policy applications of using existence value estimates to guide species conservation policy and conservation investments. We note that the implications of our study are not limited to megafauna. The spiritual significance of flora-as in the case of sacred groves located within forests (Bhagwat et al. 2005; Reddy and Yosef 2016; Vipat and Bharucha 2014) — would also increase their conservation value to society.

The model we use, its results, and policy implications are consistent with the bioeconomic literature on existence value but depart from it because of the institutional point of view in the analysis and the type of non-consumptive values considered. Clark et al. (2010) consider the case of a social portfolio manager who optimizes the net benefits of harvesting a resource for private gain with the added public benefit of its existence value for society at large. Conrad (2010) uses a similar model to consider the case of managing a whale population to optimize the net benefits from whale harvest and whale watching that provide non-consumptive direct use values. While the model setup we use here is consistent with those of Clark et al. (2010) and Conrad (2010), its formulation from the point of view of a local population, as opposed to a social planner representing society at large, the explicit modeling of existence values, and its application to terrestrial megafauna conservation, are novel. While the message is not new-conservationists have made claims that "tribal peoples are the best conservationists and guardians of the natural world" (Rust 2016) — the argument, within the context of a bioeconomic model, has not been widely applied to natural resources with spiritual value.

The conservation economics literature investigates different policy approaches available to conserve species. According to Skonhoft (1998), providing locals with benefits from hunting and tourism can reduce incentives for illegal poaching. However, Fischer et al. (2011) find that whether benefit sharing provides conservation incentives depends on the design of the benefit shares, the size of the benefits relative to agricultural losses, and the management of hunting quotas. Bulte and Rondeau (2007) consider another policy tool, compensation payments, and find that these payments have ambiguous effects on wildlife stocks and local welfare. While they can reduce hunting effort, these payments can also provide incentives to convert wildlife habitat into agricultural land. Conservation performance payments are yet another policy tool, which consists of payments for environmental services - either monetary or in-kind payments-made by an agency to individuals or groups and are conditional on specific conservation outcomes (Albers and Ferraro 2006; Engel et al. 2008). Focusing on the case of co-existence of tiger and livestock, Zabel et al. (2011) find that conservation performance payments can generate enough incentives for livestock herders to refrain from hunting so that the carnivore population reaches its socially optimal level. 
We contribute to the conservation economics literature by estimating the non-use existence values that explain the patterns of non-extinction observed in the case of the Bengal tiger and show that the policy of expulsion and/or exclusion of local tribes in the name of conservation may well lead to extinction. Conversely, conservation policies which recognize that wildlife existence values lead to species survival and secure a tribe's property rights outperform conservation policies that exclude tribes venerating a species or natural environment. The related literature lacks such existence value estimates of wildlife that provide spiritual services. More broadly, the conservation economics and non-market valuation literature lack marginal non-use benefit functions that can guide wildlife conservation policy (Eiswerth and Kooten 2009). Instead, the literature mostly includes analyses of traditional policies consisting of monetary or physical incentives and disincentives in the presence of wildlife-livestock or agriculture conflict.

The paper is structured as follows: Sect. 2 introduces the theoretical model of non-use existence values and provide the economic rationale for its steady-state equilibrium conditions. In Sect. 3, we apply the model to study the existence value of tigers for the Soligas tribe residing in and around the BRT Tiger Reserve. We generate an existence value weight of tigers under the current situation and proceed to estimate the existence values at the steady state tiger population that results under various hypothetical policy scenarios. Furthermore, we illustrate how the calibrated model can be used to generate a marginal existence value function for the tiger. In Sect. 4, we discuss the policy scenario simulations resulting from the application of the bioeconomic model and conclude with pertinent conservation policy observations.

\section{The Existence Value Model}

Clark et al. (2010) consider the case of a social portfolio manager who optimizes the net benefits of harvesting a resource for private gain with the additive public benefit of its existence value. We set up the discrete-time version of the Clark et al. optimization framework and formulate it from the standpoint of the tribe or community living around the resource as shown in Eq. (1). ${ }^{2}$

$$
\begin{gathered}
\underset{\left\{Y_{t}\right\}_{0}^{\infty}}{\operatorname{maximize}} W=\sum_{t=0}^{\infty} \rho^{t}\left[\pi\left(Y_{t}, X_{t}\right)+V\left(X_{t}\right)\right] \\
\text { subject to } X_{t+1}=X_{t}+F\left(X_{t}\right)-Y_{t}, X_{0}>0, \text { and } \lim _{t \rightarrow \infty} \rho^{t} \lambda_{t} X_{t}=0 \\
\pi_{Y}>0, \pi_{X}>0, \pi_{Y Y}<0, \pi_{X X} \leq 0, \text { and } \lim _{X \rightarrow 0} V^{\prime}(X)=\infty .
\end{gathered}
$$

The function $\pi\left(Y_{t}, X_{t}\right)$ is the private benefit minus harvest cost, where $Y_{t}$ is the extraction and $X_{t}$ is the resource stock. This net benefit function indicates the possibility of extraction from the resource for private gain. Harvest cost increases with $Y_{t}$ and reduces with $X_{t}$-signifying that as the resource becomes scarce, it becomes more costly tsource and harvest it (Clark et al. 2010; Conrad 2010). The function $V\left(X_{t}\right)$ respresents the

\footnotetext{
${ }^{2}$ A tribe's standpoint can be represented by a tribe manager who, in practice, can be a tribe's elder or other authority, depending on a tribe's socio-political structure.
} 
additive existence vue derived from its public good charcteristic. As in (Clark et al. 2010), we assume for the existence value function that its marginal value approaches infinity as the stock is depleted, i.e., $\lim _{X \rightarrow 0} V^{\prime}(X)=\infty$ The discount factor, $\rho$, is equal to $1 /(1+\delta)$, where $\delta$ is the capital interest rate in the market. The iterative map $X_{t+1}=X_{t}+F\left(X_{t}\right)-Y_{t}$ captures the evolution of the resource stock, where $F\left(X_{t}\right)$ represents the stock's growth during period $t, X_{0}>0$ is the initial level of the resource stock, and $\lim _{t \rightarrow \infty} \rho^{t} \lambda_{t} X_{t}=0$ is the transversality condition that, as $t \rightarrow \infty$, the discounted value of the resource stock becomes zero so as to ensure a maximum (Conrad 2010).

The Lagrange expression for this infinite horizon, discrete-time problem assumes the foowing form

$$
L=\sum_{t=0}^{\infty} \rho^{t}\left\{\pi\left(Y_{t}, X_{t}\right)+V\left(X_{t}\right)+\rho \lambda_{t+1}\left[X_{t}+F\left(X_{t}\right)-Y_{t}-X_{t+1}\right]\right\}
$$

The first-order necessary conditions are accordingly derived for the control variable $\left(Y_{t}\right)$, state variable $\left(X_{t}\right)$, and co-state variable $\left(\rho \lambda_{t+1}\right)$.

$$
\begin{gathered}
\frac{\partial L}{\partial Y_{t}}=\rho^{t}\left\{\frac{\partial \pi(.)}{\partial Y_{t}}-\rho \lambda_{t+1}\right\}=0 \\
\frac{\partial L}{\partial X_{t}}=\rho^{t}\left\{\frac{\partial \pi(.)}{\partial X_{t}}+\frac{\partial V(\cdot)}{\partial X_{t}}+\rho \lambda_{t+1}\left[1+\frac{\partial F(\cdot)}{\partial X_{t}}\right]-\lambda_{t}\right\}=0 \\
\frac{\partial L}{\partial \rho \lambda_{t+1}}=\rho^{t}\left\{X_{t}+F\left(X_{t}\right)-Y_{t}-X_{t+1}\right\}=0
\end{gathered}
$$

The three first-order conditions can be solved for the steady-state equilibrium in which the three variables are unchanging with time. We carry this out by dropping the time $(t)$ subscripts from the variables, i.e. $Y_{t+1}=Y_{t}=Y, X_{t+1}=X_{t}=X, \lambda_{t+1}=\lambda_{t}=\lambda$

$$
\begin{gathered}
\pi_{Y}-\rho \lambda=0 \\
\pi_{X}+V_{X}+\rho \lambda\left[1+F_{X}\right]-\lambda=0 \\
Y-F(X)=0
\end{gathered}
$$

In steady-state, Eq. (6) implies that a harvester would extract until the marginal benefit of harvest equals the discounted shadow price of the resource in the next time period; essentially, it is the user cost of the resource. $\lambda$. is the value of an additional unit of the resource in period $t$. Equation (7) implies that if this resource is to be optimally managed, then the marginal value of the resource must equal its marginal net benefit $\left(\pi_{X}(\cdot)+V_{X}(\cdot)\right)$.plus the discounted marginal benefit of an unharvested unit of the resource that accrues in the following period $\left(\rho \lambda\left[1+F_{X}(\cdot)\right]\right)$. This total marginal benefit must reflect the value of an additional unit of the resource, $\lambda$. Equation (8) implies that in steady-state, the resource is neither growing nor diminishing over time or that harvest equals the growth in each $t$ ing the ft that $\rho=1 /(1+\delta)$ and rearranging Eqs. (6), (7), and (8) we derive Eq. (9). 


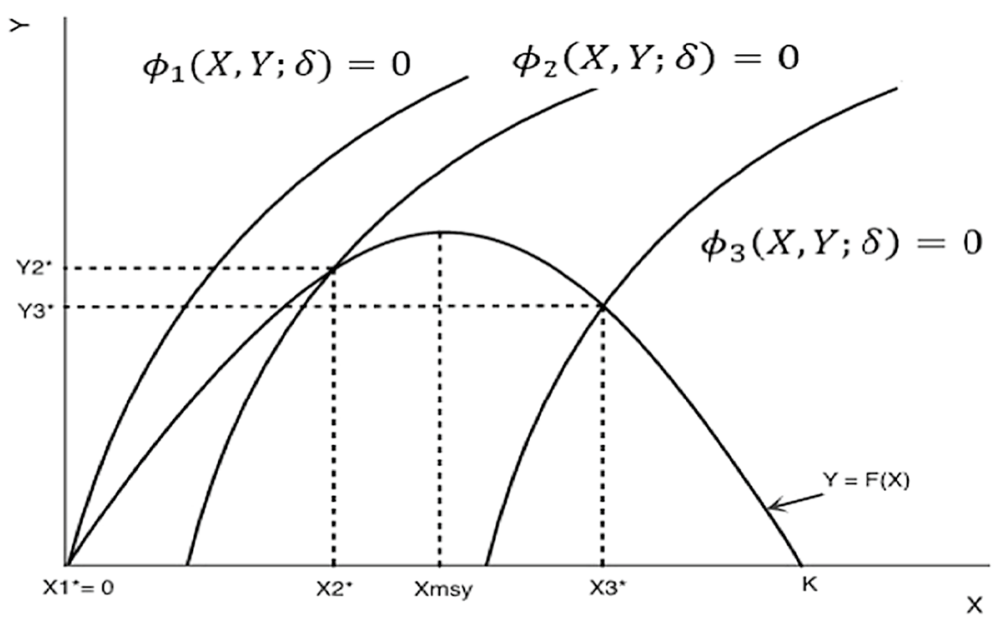

Fig. 1 Representing the fundamental equation of renewable resources in $(X-Y)$ space: existence values in $\phi_{2}(X, Y ; \delta)$ or $\phi_{3}(X, Y ; \delta)$ lead to steady states with species survival

$$
\frac{\pi_{X}(\cdot)+V_{X}(\cdot)}{\pi_{Y}(\cdot)}+F_{X}(\cdot)=\delta
$$

Equation (9) is the well-known fundamental equation of renewable resources with the addition of the marginal benefit of existence value (Clark et al. 2010). The first term on the left-hand side of (9) is the ratio of the marginal value of $X$ relative to the marginal value of $Y$. This is also referred to as the marginal stock effect (Conrad 2010). The second term is the marginal net growth rate of $X$. Their sum must equal the rate of interest in the capital market for optimal resource management. On substituting $Y=F(X)$ from (8) into (9), we can solve for the pair of steady-state values $\left(X^{*}, Y^{*}\right)$. Equation (9) would yield a curve in the $(X-Y)$ space in implicit form $\phi(X, Y ; \delta)=0$. Three representative curves are shown in Fig. $1 \phi_{1}(X, Y ; \delta)$ implies that extinction might be optimal (i.e. $X_{1}^{*}=0$ ) when either $X$ grows too slowly, $\delta$ is very high, or the market price is much higher than the harvest cost of the last rource unit (Conrad 2010). For the steady-state value $X_{2}^{*}$, the marginal stock effect is less th $\delta$ since $F^{\prime}(X)>0$. For the steady-state value $X_{3}^{*}$, the marginal stock effect is greater than $\delta$, and thereby it might be optimal to have a higher steady-state value of $X$; this is shown below to be greater than the stock level at the maximum sustainable yield or the highest growth rate of the resource (i.e. $X_{m s y}$ ).

Wcan numerically solve for pairs of steady-state values $\left(X^{*}, Y^{*}\right)$ by specifying functional forms for $\pi(\cdot), V(\cdot)$, and $F(\cdot)$, and parameterizing the mel. Once we have our $\left(X^{*}, Y^{*}\right)$ values, we can then simulate the evolution of $X(t)$ and $Y(t)$ over time and examine if their approach paths converge to the analytical steady-states when the initial values of resource stock and harvest are different from them, i.e., if $X_{0} \neq X^{*}$ and $Y_{0} \neq Y^{*}$. In Sect. 3.1, we will assume functional forms for $\pi(\cdot), V(\cdot)$, and $F(\cdot)$, and calibrate the model fhe tiger population in the BRT tiger reserve in southwestern India with t resident Sigas tribe. 


\section{Applying the Model to a Tiger Population and a Resident Tribe}

In this section, we will apply the model to the Soligas tribe and the tiger population ithe BRT. Our baseline scenario is taken to represent the current situation in the BRT wrein the Soligas have community rights in accordance with the Forest Rights Act and all poaching is subject to a penalty as per the Indian Wildlife Protection Act. Given the indefiniteness with which property rights were either granted or taken away in India's past, we shall consider hypothetical policy scenarios in the presence and absence of such rights. Furthermore, we will analyze these scenarios in the presence and absence of a poaching penalty. These hypothetical scenarios that we shall analyze will enable us to examine an array of pathways that could arise if the enforcement of land claims and the imposition of poaching penalties were to change in the future. The institutional perspective that we adopt for the baseline scenario is from the point of view of a tribe manager who maximizes the expression $\mathbb{E}\left[W^{B}\right]$ as per Eq. (10).

$$
\underset{\left\{Y_{t}\right\}_{0}^{\infty}}{\operatorname{maximize}} \mathbb{E}\left[W^{B}\right]=\sum_{t=0}^{\infty} \rho^{t}\left[p Y_{t}-(c / 2) Y_{t}^{2} / X_{t}-\left(Y_{t} / X_{t}\right) e^{\left(\theta\left(1-Y_{t} / X_{t}\right)\right)} \cdot B+\beta \ln \left(X_{t}\right)\right]
$$

subject to $X_{t+1}=X_{t}+r X_{t}\left(1-X_{t} / K\right)-Y_{t}, X_{0}>0$ given $\theta \leq 0$, and $\lim _{t \rightarrow \infty} \rho^{t} \lambda_{t} X_{t}=0$.

We assume that $\pi\left(X_{t}, Y_{t}\right)=\left(p Y_{t}-(c / 2) Y_{t}^{2} / X_{t}-\left(Y_{t} / X_{t}\right) e^{\left(\theta\left(1-Y_{t} / X_{t}\right)\right)} . B\right)$. We define $p$ as the per unit price of the harvested resource and $c$ as a harvest cost parameter.arvesting the tiger resource attracts a poaching penalty, and with this penalty in place, there is a chance that the harvester would be caught poaching by conservation authorities. Wume that a greater amount of illegal activity increases the chance of being caught (Copeland and Taylor 2009). We consider an exponential probability density function (Pishro-Nik 2014)f the following form: $\omega\left(Y_{t}, X_{t}\right)=\left(Y_{t} / X_{t}\right) e^{\left(\theta\left(1-Y_{t} / X_{t}\right)\right)}$. In this probability density fction we have $\theta \leq 0$ and $X_{t} \geq Y_{t} \geq 0$, and it indicates that as illegal harvest increases so does the chance of being caught by conservation authorities. If the harvester is caught then a penalty of $\$ \beta$ is imposed on her, and this enters as an expected payment that is deducted from her private net benefit.

Fxistence value, we assume that $V\left(X_{t}\right)=\beta \ln \left(X_{t}\right)$ where $\beta$ is an existence value weight, which can be used to determine the magnitude of the marginal existence value of $X$. We show later in the numerical analyses that the marginal existence value increases rapidly with a decline in the tiger population. Eiswerth and Kooten (2009) note that nonlinear nonuse benefit functions (such as logarithmic benefit functions) are more realistic, more consistent with empirical findings (e.g., Desvousges et al. 1992; Loomis and Larson 1994), and result in more accurate estimates of $X^{*}$ in numerical estimations. These functions satisfy the necessary assumptions for an interior solution: $\pi_{Y}>0, \pi_{X}>0, \pi_{Y Y}<0, \pi_{X X} \leq 0$, and $\lim _{X \rightarrow 0} V^{\prime}(X)=\infty$ (Clark et al. 2010). The tiger population grows as per a standard logistic growth function $F\left(X_{t}\right)=r X_{t}\left(1-X_{t} / K\right)$, where $r$. is the intrinsic growth rate and $K$. is the environment's carrying capacity.

For the discrete-time infinite horizon optimization problem in (10), one can set up the Lagrangean $\left(L^{B}\right)$, derive the first-order necessary conditions in sy-ate, and substitute $Y=F(X)=r X(1-X / K)$ to get the fundamental equation of rewable resources, $(\phi(X, F(X) ; \delta, B) \equiv 0)$ in Eq. (11); this fundamental equation accounts $\mathrm{f}$ the existence value within the tribe manager's decision framework. In contrast, Eq. (11.1) represents the 
fundamental equation of renewable resources in the presence of a poaching penalty but without the addition of existence value.

$$
\begin{gathered}
L^{B}=\sum_{t=0}^{\infty} \rho^{t}\left\{p Y_{t}-(c / 2) Y_{t}^{2} / X_{t}-\left(Y_{t} / X_{t}\right) e^{\left(\theta\left(1-Y_{t} / X_{t}\right)\right)} \cdot B\right. \\
\left.+\beta \ln \left(X_{t}\right)+\rho \lambda_{t+1}\left[X_{t}+r X_{t}\left(1-X_{t} / K\right)-Y_{t}-X_{t+1}\right]\right\} \\
\phi(\cdot) \equiv \frac{c}{2} r^{2}\left(1-\frac{X}{K}\right)^{2}+B \cdot r\left(1-\frac{X}{K}\right) e^{(\theta(1-r(1-X / K)))}[1-\theta r(1-X / K)]+\frac{\beta}{X} \\
+\left[p-c r\left(1-\frac{X}{K}\right)-\frac{B}{X} e^{(\theta(1-r(1-X / K)))}[1-\theta r X(1-X / K)]\right]\left[r\left(1-\frac{2 X}{K}\right)-\delta\right]=0 \\
\phi(\cdot) \equiv \frac{c}{2} r^{2}\left(1-\frac{X}{K}\right)^{2}+B \cdot r\left(1-\frac{X}{K}\right) e^{(\theta(1-r(1-X / K)))}[1-\theta r(1-X / K)] \\
+\left[p-c r\left(1-\frac{X}{K}\right)-\frac{B}{X} e^{(\theta(1-r(1-X / K)))}[1-\theta r X(1-X / K)]\right]\left[r\left(1-\frac{2 X}{K}\right)-\delta\right]=0
\end{gathered}
$$

In Eq (12), we consider the modalities of an alternative policy scenario where the tribe possesses land rights but there is no poaching penalty impositionWe therefore assume that $\pi\left(X_{t}, Y_{t}\right)=\left(p Y_{t}-(c / 2) Y_{t}^{2} / X_{t}\right)$. The optimization problem for the tribe manager is accordingly set up as follows:

$$
\underset{\left\{Y_{t}\right\}_{0}^{\infty}}{\operatorname{maximize}} W=\sum_{t=0}^{\infty} \rho^{t}\left[p Y_{t}-(c / 2) Y_{t}^{2} / X_{t}+\beta \ln \left(X_{t}\right)\right]
$$

subject to, $X_{t+1}=X_{t}+r X_{t}\left(1-X_{t} / K\right)-Y_{t}, X_{0}>0$, and $\lim _{t \rightarrow \infty} \rho^{t} \lambda_{t} X_{t}=0$.

We set up the Lagrangean $(L)$ for this infinite time horizon optimization problem, derive the first-order necessary conditions in steady-state, and substitute $Y=F(X)=r X(1-X / K)$ to get the fundamental equation of renewable resources, $\phi(X, F(X) ; \delta) \equiv 0$ in Eq. (13). The tribe manager explicitly accounts $f$ the existence value in (13), whereas (13.1) represents the fundamental equation of renewable resources without the addition of existence value and therefore solves for the outcome of a harvester.

$$
\begin{gathered}
L=\sum_{t=0}^{\infty} \rho^{t}\left\{p Y_{t}-(c / 2) Y_{t}^{2} / X_{t}+\beta \ln \left(X_{t}\right)+\rho \lambda_{t+1}\left[X_{t}+r X_{t}\left(1-X_{t} / K\right)-Y_{t}-X_{t+1}\right]\right\} \\
\phi(\cdot) \equiv \frac{c}{2} r^{2}\left(1-\frac{X}{K}\right)^{2}+\frac{\beta}{X}+\left[p-c r\left(1-\frac{X}{K}\right)\right]\left[r\left(1-\frac{2 X}{K}\right)-\delta\right]=0 \\
\phi(\cdot) \equiv \frac{c}{2} r^{2}\left(1-\frac{X}{K}\right)^{2}+\left[p-c r\left(1-\frac{X}{K}\right)\right]\left[r\left(1-\frac{2 X}{K}\right)-\delta\right]=0
\end{gathered}
$$

We can now calibrate our model for the BRT tiger reserve and numerically solve the fundamental equations of renewable resources to derive the steady-state values $\left(X^{*}, Y^{*}\right)$ under different policy scenarios. Ideally, we would have different data for each of the policy scenarios we consider so we could conduct scenario-specific model calibrations. In 
Table 1 Empirical parameters for model simulation

\begin{tabular}{llll}
\hline Parameter & & Value & Source \\
\hline Tiger growth rate & $r=$ & 0.05 & Smirnov and Dale (1999), WWF (2016) \\
Carrying capacity & $K=$ & 86 tigers & Damodaran (2007), KFD (2017) \\
Initial stock & $X_{0}=$ & 35 tigers & Varma (2015) \\
Harvest cost & $c=$ & $\$ 216$ & GOI (2018), WPSI (2010) \\
Poaching price & $p=$ & $\$ 36 /$ tiger & Damania et al. (2003) \\
Discount rate & $\delta=$ & 0.08 & \\
Tence weight & $\beta=$ & $150-900$ & \\
Penalty & $B=$ & $\$ 769$ & MOEF (2013) \\
Probability parameter & $\theta=$ & -5 & Authors' calculation \\
\hline
\end{tabular}

practice, however, poaching data are typically not available or underreported in developing countries like India; WPSI (2019) compiles limited data on tiger poaching, but that too is only a fraction of the actual number of poaching offences. Instead, we design hypothetical policy scenarios (i.e., PS2-PS4 described in Sect. 3.1) to represent cases that differ in whether property rights are secured and whether a policy instrument is imposed. Table 1 lists the model's parameters as applied for the BRT Tiger Reserve and its resident Soligas tribe.

Smirnov and Dale (1999) estimate the tigers grow at an annual rate of $r=0.06$. However, this value of $r$ might be overestimating the growth rate of tigers in the wild. According to tiger census reports global tiger population increased from 3200 in the year 2010 to 3890 by the year 2016 (WWF 2016); these figures yield an annual growth rate of approximately 0.04 . We consider an average rate of $r=0.05$ to account for overestimation or underestimation. Damodaran (2007) reports wild habitat carrying capacity as 6.25 tigers per square kilometer. The BRT Tiger Reserve is $540 \mathrm{~km}^{2}$ (KFD 2017), which implies a carrying capacity o $K=\frac{540}{6.25}=.86$ tigers. The BRT Tiger Reserve had approximately 35 tigers around 2010 (Varma 2015); accordingly, we aume $X_{0}=35$.

Asiderable amount of planning and time goes into killing a tiger. According to investigations and reported poachers' confessions, poaching takes between 3 and 4 weeks for a kill from planning to execution (WPSI 2010). Poachers sometimes use rudimentary traps to snare tigers and kill them. These traps are low-cost (approximately $\$ 3.50$ per trap). One could use the daily wage rate in India to estimate the opportunity cost of poaching. The daily labor wage rate is INR272 (US\$4.18) per day in India (GOI 2018). We use this information to arrive at a value for our harvest cost parameter, $c=(272 \times 25+3.5 \times 65 / 65) \times 2=\$ 216$ by assuming twenty-five days are devoted to a tiger poaching expedition. ${ }^{3}$ The poacher carries the tiger skin and body parts back to the village, where he/she eventually sells it to middlemen. Poachers might receive only as little as INR1000 per tiger (Damania et al. 2003). Accounting for inflation (WB 2017), and converting to US\$, we derive a poaching price value of $(1000 \times 141 / 61) / 65=\$ 36$ per tiger. $^{4}$ We assume a rate of time preference $\delta=0.08$ in developing countries as used by (Zabel

\footnotetext{
3 The expression is multiplied by 2 because in the cost function in $\pi\left(X_{t}, Y_{t}\right)$ we have $c / 2$. This value of $c=$ $\$ 216$ is slightly higher that the cost estimate of $c=\$ 180$ for poaching expeditions reported in Bulte and van Kooten (1999a) and Milner-Gulland and Leader-Williams (1992).

4 The price received by poachers is not to be confused with buyer black market prices, which can reach $\$ 15,000-\$ 20,000$ (Damania et al. 2003).
} 
et al. 2009). ${ }^{5}$ Any amount of poaching is considered illegal in India, and the penalty is set at INR50000 (i.e., $B=\$ 769$ ) as per the Indian Wildlife Protection Act (MOEF 2013).

Fstly, with the given set of parameters in Table 1, including the reported estimate of current tiger population in the BRT Reserve (i.e. $X_{0}=35$ ) and growth and poaching parameters, we use the fundamental equation of renewable resources to derive the numerical steady-state values of tiger population $\left(X^{*}\right)$, poaching harvest $\left(Y^{*}=F\left(X^{*}\right)\right)$., and existence weight $(\beta)$. The numerical derivation uses the programmable non-linear Solver function in Excel and involves assuming initial guesses for the variable and/or parameters being estimated. Our initial guess for $X^{*}$. is set at the observed population of $X_{0}=35$, and we consider a wide range of initial existence weights of $\beta$ between 150 and 900 as listed in Table 1. Based on the policy scenarios we will discuss in Sect. 3.1, Solver yields estimates of $X^{*}, Y^{*}=F\left(X^{*}\right)$, and $\beta$. Under this revealed preference estimation technique, we use the baseline policy scenario representing the current BRT situation to numerically back out the unique existence value parameter $(\beta)$. This existence value weight of $\beta$ is further applied to the alternative policy scenario to simulate outcomes that might result under regime shifts. The numerical exercise will reveal if the system is already in a steady-state or not by seeing if the observed $X_{0}=X^{*}$ econdly, we will use the iterative map $\left[X_{t+1}=X_{t}+F\left(X_{t}\right)-Y_{t}\right]$ to simulate the evolution of $X(\mathrm{t})$ and examine if its approach path converges to $X^{*}$ if the initial stock is not yet at the steady-state, i.e. if $X_{0} \neq X^{*}$. We will examine the approach paths that represent tiger population dynamics under the various policy scenarios.

\subsection{Tigerr Different Policy Scenarios}

\subsubsection{Secured Property Rights and Poaching Penalty}

The first policy scenario that we consider is one where the resident Soligas tribe has secure property rights to the tiger resource, faces penalty imposition for poaching, the tribe collectively manages the resource in a way that is not myopic, and the inclusion of existence value in the optimization problem. This scenario is designed to represent the current situation in the BRT. Equation (11) can be numerically solved to derive steady-state values $\left(X^{*}, Y^{*}\right)$ for the parameters in Table $1 B=\$ 769$. and $\theta=-5$ are the penalty function parameters where $B$ is the penalty amount and $\theta<0$ yields a positive probability, i.e. $e^{\left(\theta\left(1-Y_{t} / X_{t}\right)\right)} \geq 0$. We accordingly derive $X^{*}=56.557$. and $Y^{*}=F\left(X^{*}\right)=0.968$. We use Solver at the same time to back out an existence value weight of $\beta=167.50$, which yields a steady-state existence value of $\beta \ln \left(X^{*}\right)=675.92 .{ }^{6}$ This numerical estimate of $\beta$, which is backed out using a calibration that rresents the current situation in the BRT, is essentially a revealed preference parameter tt can bused to estimate the tiger's spiritual ecosystem service value from the perspective othe Soligas tribe manager. Using this perspective, the $\beta$ value is unique to the Soligas, given the current situation in the BRT. Thus, $\beta=167.50$ would be applicable to any policy scenario, and as such would be considered a given value that represents the Soligas preferences, regardless of policy regime shifts.

\footnotetext{
5 Individuals or a society with higher rates of mortality, and thus shorter life expectancy, are likely to exhibit higher rates of time preference. The value of $\delta=0.08$ is in the range estimated for developing countries.

6 This exercise circumvents the arbitrariness of an assumed value of $\beta$ and the possibility of multiple steady states based on this assumption.
} 
Fig. 2 Approach paths of $X(t)$ with and without existence value in the presence of secure property rights for Soligas and poaching penalties

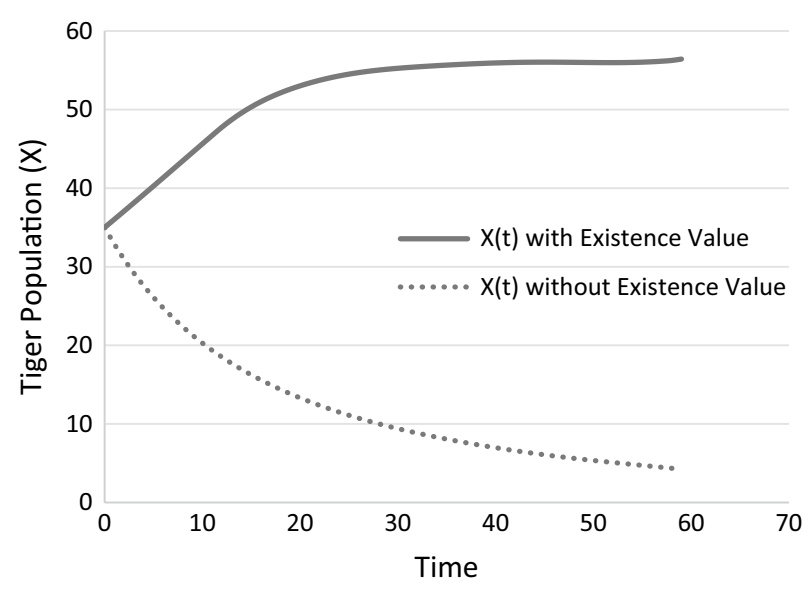

Aing backed out the $\beta$ value, we will now examine if the approach path of $X(t)$ converges to the equilibrium value, given that the initial resource stock is not at the steadystate. In order to simulate our infinite-horizon problem, we will use the concept of a final function (Conrad 2010). A correctly specified final function allows one to approximate the approach to a steady-state in an infinite-horizon problem by converting it to a finite-horizon problem. Let us revisit the tribe manager's optimization problem listed in Eq. (10) and rewrite it as Eq. (14).

$$
\begin{aligned}
\operatorname{maximize} \mathbb{E}\left[W^{B}\right]= & \sum_{(t=0)}^{(T-1)} p^{t}\left[p Y_{c}-(c / 2) Y_{t}^{2} / X_{t}-\left(Y_{t} / X_{t}\right) e^{\left(\theta\left(1-Y_{t} / X_{t}\right)\right)} \cdot B+\ln \left(X_{t}\right)\right] \\
& +\left(P^{(T-1)}\left\{p r X_{T}\left(1-X_{T} / K\right)-\frac{C}{2 X_{T}}\left[r X_{T}\left(1-X_{T} / K\right)\right]^{2}-B \cdot r\left(1-\frac{X_{T}}{K}\right) e^{\left(\theta\left(1-r\left(1-X_{T} / K\right)\right)\right)}+\beta \ln \left(X_{T}\right)\right)\right\} / \delta
\end{aligned}
$$

$$
\text { subject to } X_{t+1}=X_{t}+r X_{t}\left(1-X_{t} / K\right)-Y_{t} \text { and } X_{0}>0 \text { given }
$$

The objective function $W^{B}$ is the sum of the present value of net benefits over time $t=0,1,2, \ldots, T-1$ and some final function, $\psi\left(X_{T}\right)$, in Eq. (15):

$$
\begin{aligned}
\psi\left(X_{T}\right)= & \frac{\rho^{T-1}}{\delta}\left\{p r X_{T}\left(1-X_{T} / K\right)-\frac{c}{2 X_{T}}\left[r X_{T}\left(1-X_{T} / K\right)\right]^{2}\right. \\
& \left.-B \cdot r\left(1-\frac{X_{T}}{K}\right) e^{\left(\theta\left(1-r\left(1-X_{T} / K\right)\right)\right)}+\beta \ln \left(X_{T}\right)\right\}
\end{aligned}
$$

The final function can be thought of as the value of maintaining $X_{T}$ for $t=T, T+1, \ldots, \infty$ by harvesting $Y_{t}=r X_{T}\left(1-X_{T} / K\right)$ for the rest of me in steady-state. With $Y_{t}=r X_{T}\left(1-X_{T} / K\right)$ being a constant, it can be factored out of the infinite series with the present value converging to $\psi\left(X_{T}\right)$. Using the parameters in Table 1, assuming an initial value of $X_{0}=35, T=60$ years, and assigning initial value guesses for $\left\{Y_{t}\right\}_{t=0}^{t=59}=0.10$, we numerically estimate the approach paths of $X(t)$ and $Y(t)$ over the horizon of $T=60$. years. Using Solver, we find convergence to a maximum value for the objective function, $\mathbb{E}\left[W^{B}\right]=8691.1$. Moreover, we note that $X_{t}=56.5$ as $t \rightarrow 60$, which implies that the approach path of the resource stock indeed approaches the steady-state $\mathrm{v}$ of $X^{*}$ as derived 


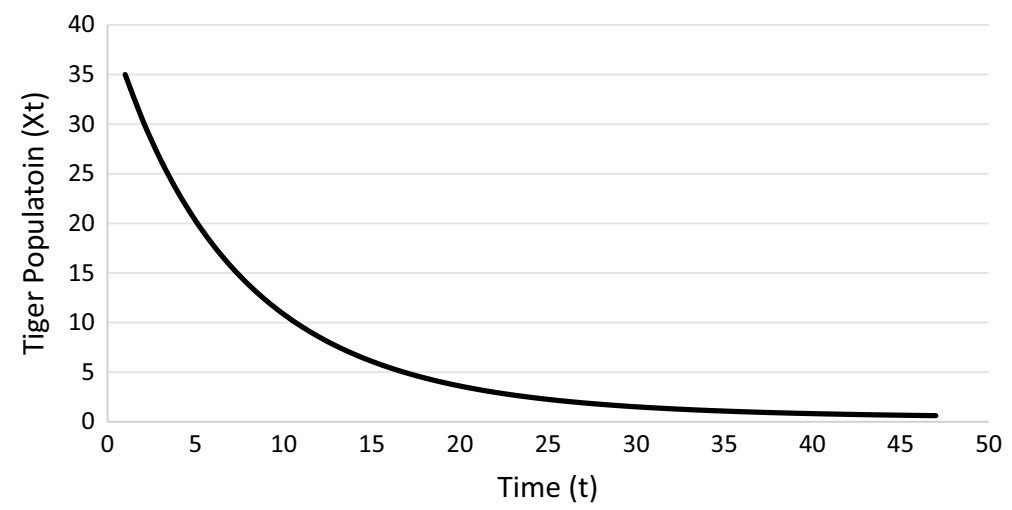

Fig. 3 Approach path of $X(t)$ without secure property rights to sacred tigers and penalty imposition

from Eq. (11). This approach path of $X_{t}$ is shown in Fig. 2. This policy result wld correspond to the implicit equation $\phi_{2}(X, Y ; \delta)$ or $\phi_{3}(X, Y ; \delta)$ in Fig. 1 that yieldedteady-state equilibriums over time. The dotted line in Fig. 2 depicts the approach path of $X_{t}$ whout thexistence value; in this scenario the existence value, $\beta \ln \left(X_{t}\right)$, drops out of the optimization framework according to Eq. (11.1). The dotted line approach path allows one to examine the effect of excluding existence value from the tribe manger's decision framework.

proach paths of $X(t)$. with and without existence value in the presence of secure property rights for Soligas and poaching penalties.

\subsubsection{Exclusion Conservation Policy with a Poaching Penalty}

In the second policy scenario, we consider the case where the tribe's property rights to the sacred tiger forest are taken away by authorities in the name of conservation, and poaching continues to attract a penalty. In this case, we make the assumption that insecure property rights lead to a myopic harvesting of the tiger (Skonhoft and Solstad 1996). The myopic harvester would accordingly treat the tiger stock $X_{\mathrm{t}}$ as a parameter in each $t$. Thereby, the harvester would maximize net benefits myopically in each $t$ without concern for how the current period's harvest affects the resource in the following period, i.e. $X_{t+1}$. This would imply that $\rho \lambda_{t+1}=0$ in the Lagrangean used for Eq. (11). The optimization problem is written as $\mathbb{E}\left[W^{B}\right]$ in Eq. (16) and the corresponding first-order necessary condition, Eq. (17), can be numerically solved to yield $Y_{t}$ in each $t$ by using the parameters from Table 1.

$$
\begin{gathered}
\underset{Y_{t}}{\operatorname{maximize}} \mathbb{E}\left[W^{B}\right]=\left\{p Y_{t}-(c / 2) Y_{t}^{2} / X_{t}-\left(Y_{t} / X_{t}\right) e^{\left(\theta\left(1-Y_{t} / X_{t}\right)\right)} \cdot B+\beta \ln \left(X_{t}\right)\right\} \\
\frac{\partial \mathbb{E}\left[W^{B}\right]}{\partial Y_{t}}=p-\frac{c Y_{t}}{X_{t}}-B \cdot \frac{e^{\left(\theta\left(1-Y_{t} / X_{t}\right)\right)}}{X_{t}}\left(1-\theta Y_{t} / X_{t}\right) \equiv 0
\end{gathered}
$$

This first-order necessary condition can be solved numerically using Sver to equate it to zero by finding the harvest $Y_{t}$, with $X_{t}$ treated as a parameter. One would note that the existence value $\beta \ln \left(X_{t}\right)$ does not feature in this myopic harvester's decision as per Eq. (17). Once again, the initial resource stock is $X_{0}=35$ tigers. Once Sver yields the initial harvest, $Y_{0}$, the iterative map $\left[X_{t+1}=X_{t}+F\left(X_{t}\right)-Y_{t}\right]$ is called upon to derive $X_{1}$, and the exercise 
Fig. 4 Approach paths of $X(t)$ with and without existence value in the presence of secure property rights for Soligas to sacred tigers

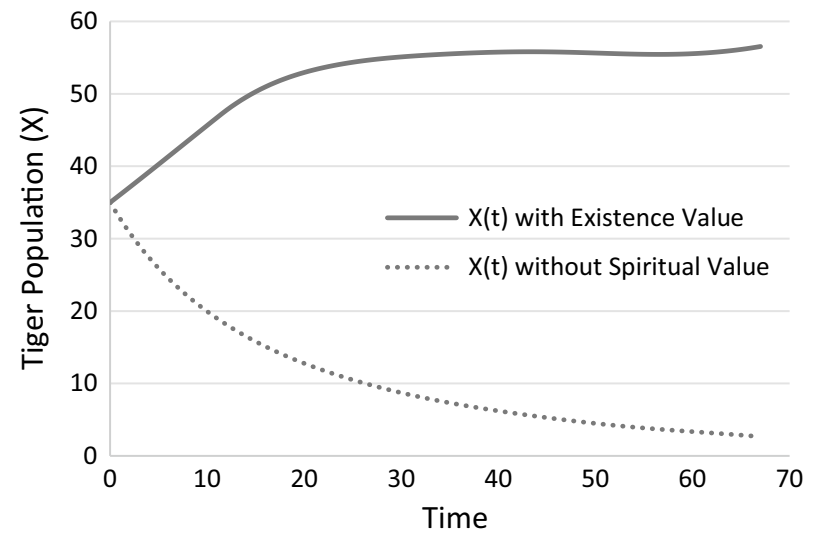

is repeated for $t=1,2, \ldots, T$. In the approach path shown in Fig. 3, we observe that the resource stock $X_{t} \rightarrow 0$ and tiger extinction in the BRT occurs in 49 years. Extinction occurs in consonance with the implicit equation, $\phi_{1}(X, Y ; \delta)=0$, that yielded localized tiger einction in the phase diagram of Fig. 1. This implies that extinction is optimal when poaching idriven up by the harvester's myopic behavior with a high discount rate $\delta$ that results in $X$ gwing slower than the offtake.

\subsubsection{Sured Property Rights with no Poaching Penalty}

The third policy scenario that we consider is one where the resident Soligas tribe has secure property rights to the tiger resource and the tribe collectively manages the resource in a way that is not myopic as under Scenario 3.1.1, and that includes the existence value in the optimization problem. The departure from Scenario 3.1.1 is the absence of a poaching penalty. The parameter values in Table 1 are substituted into Eq. (13) to numerically solve for the steady-state values of resource stock $\left(X^{*}\right)$. and harvest $\left(Y^{*}\right)$ by using Solver. Under Scenario 3.1.1, we backed out the value of $\beta$ as 167.50; this weight is the preference parameter of the Soligas tribe as to the tiger's existence. Using Solver, we derive the steadystate equilibrium values we derive are $X^{*}=56.003$ and $Y^{*}=F\left(X^{*}\right)=0.976$, with $\beta$ set at 167.50. This situation would correspond to the implicit equation $\phi_{2}(X, Y ; \delta)$ or $\phi_{3}(X, Y ; \delta)$ in Fig. 1 that yielded steady-state equilibriums over time. The existence weight of $\beta=167.50$ yields a steady-state existence value of $\beta \ln \left(X^{*}\right)=674.27$; this value is not meaningfully different fm the 675.92 derived under Scenario 3.1.1. Next, we examine the resource's approach path when $X_{0} \neq X^{*}$ by using the final function method described earlier. In order to do this, we risit t tribe manager's optimization problem listed in Eq. (12) and rewrite it as Eq. (8).

$$
\begin{aligned}
\underset{\left\{Y_{t}\right\}_{0}^{T-1}}{\operatorname{maximize}} W^{f}= & \sum_{t=0}^{T-1} \rho^{t}\left[p Y_{t}-(c / 2) Y_{t}^{2} / X_{t}+\beta \ln \left(X_{t}\right)\right] \\
& +\rho^{T-1}\left\{p r X_{T}\left(1-X_{T} / K\right)-\frac{c}{2 X_{T}}\left[r X_{T}\left(1-X_{T} / K\right)\right]^{2}+\beta \ln \left(X_{T}\right)\right\} / \delta
\end{aligned}
$$

subject to $X_{t+1}=X_{t}+r X_{t}\left(1-X_{t} / K\right)-Y_{t}$ and $X_{0}>0$ 


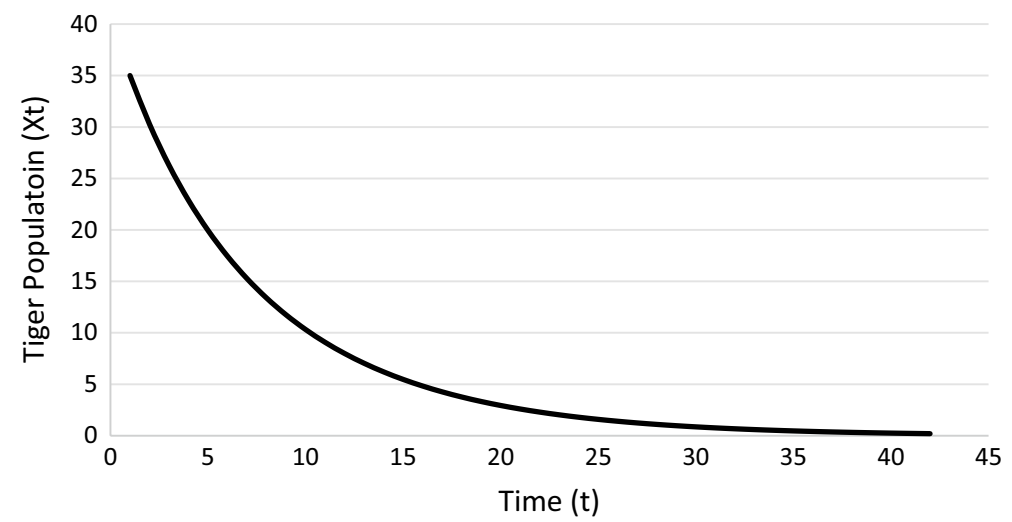

Fig. 5 Approach path of $X(t)$ without secure property rights to sacred tiger

The objective function $W^{f}$ is the sum of the present value of net benefits over time $t=0,1,2, \ldots, T-1$ and a final function, Eq. (19); i.e., the val maintaining $X_{T}$ for $t=T, T+1, \ldots, \infty$ by harvesting $Y_{t}=r X_{T}\left(1-X_{T} / K\right)$ for the rest of timin steady-state.

$$
\psi X(t)=\frac{\rho^{T-1}}{\delta}\left\{p r X_{T}\left(1-X_{T} / K\right)-\frac{c}{2 X_{T}}\left[r X_{T}\left(1-X_{T} / K\right)\right]^{2}+\beta \ln \left(X_{T}\right)\right\} .
$$

Using the parameters in Table 1, assuming an initial value of $X_{0}=35, T=70$ years, and assigning initial value guesses for $\left\{Y_{t}\right\}_{t=0}^{t=70}=0.10$, we numerically estimate the approach path of $X(t)$ over the horizon of $T=70$ years. Using Solver and setting $\beta=167.50$, we find convergence to a maximum value for the objective function, $W^{f}=8691.44$. Moreover, we note that $X_{t}=56.5$ as $t \rightarrow 70$, which implies that the approach path of the resource stock indeed approaches the steady-state value of $X^{*}$ that was derived using Equation (13). The approach path of $X_{t}$ is shown in Fig. 4. The dotted line in Fig. 4 depicts the approach path of $X_{t}$ without the existence value as derived in Eq. (13.1).

In the approach paths of Figs. 2 and 4-under policy scenarios 3.1.1 and 3.1.3-we note that the tiger populations converge to the steady-state populations of $X^{*}$ with the backedout value of $\beta$. More importantly, we note that the initial value of $X_{0}=35$ is entirely exogenous to our simulations; this implies that even with an exogenous initial value in our model, we do observe convergence to the numerically-derived steady-state with the backed-out $\beta$ weight. This convergence to steady state using the final function approach lends a way for one to check the reliability of the numerically backed-out existence weights and the steadystate populations.

\subsubsection{Exclusion Conservation Policy with No Poaching Penalty}

Lastly, we will consider an exclusionary policy under which the Soligas do not have property rights in the BRT, and the harvesting of tigers is not associated with a poaching penalty. In this scenario, the tribe's property rights to the sacred tiger forest are taken away by conservation authorities. Similar to policy scenario 3.1.2, the harvester would maximize net benefits myopically in each $t$ without concern for how the current period's harvest affects the resource in the following period, except that there is no poaching penalty. We 
would accordingly have $\rho \lambda_{t+1}=0$ in the Lagrangean used for Eq. (13) and the harvester chooses $Y_{t}$ to maximize net benefits, $W^{n p}$, in each $t$ as per Eq. (20).

$$
\underset{Y_{t}}{\operatorname{maximize}} W^{n p}=\left\{p Y_{t}-(c / 2) Y_{t}^{2} / X_{t}+\beta \ln \left(X_{t}\right)\right\} \text {. }
$$

The first-order necessary condition yields the optimal harvest as $Y_{t}=(p / c) X_{t}$. in each $t$. Note the similarity with scenario 3.1 .2 under which the existence vue $\beta \ln \left(X_{t}\right)$ does not feature in the myopic harvester's decision. We use the parameters from Table 1 to derive the approach path of $X(t)$ in this policy scenario, i.e., without secure property rhts to the sacred tiger resource. This approach path is shown in Fig. 5 with a starting value of $X_{0}=35$ tigers. We observe that the resource stock $X_{t} \rightarrow 0$ and localized tiger extinctn in the BRT occurs as $t \rightarrow 38$ years. The absence of a poaching penalty in this policy scenario hastens extinction by 11 years compared to what was observed in the approach path in Fig. 3 Likewise, extinction occurs in consonance with the implicit equation, $\phi_{1}(X, Y ; \delta)=0$, in Fig. 1 .

\subsection{Total and Marginal Existence Values of the Bengal Tiger}

The existence values we estimate using numerical simulations can be interpreted and used for policy guidance in similar ways to those estimated using the contingent valuation (CV) method or discrete choice experiments. Although these two non-market valuation methods can estimate non-use values, they cannot be used to estimate existence values that might include spiritual values derived by indigenous populations (Adamowicz et al. 1998). Because there are no other estimates of wildlife existence values related to spirituality that we can compare our estimates to, we discuss in this section how the total and marginal existence values that can be estimated using our model have similar interpretations to total and marginal willingness-to-pay (WTP) estimates in the wildlife valuation literature. We also generate a marginal existence value function for the Bengal tiger in the BRT reserve. Marginal non-use value functions are necessary for guiding conservation policy but remain unknown for any charismatic wildlife species (Eiswerth and Kooten 2009).

Most wildlife contingent valuation studies generate total WTP estimates, as opposed to measuring the marginal benefits of increasing population numbers (Bulte and van Kooten $1999 b)$. The existence value we estimate in Policy Scenario $1, \beta \ln \left(\mathrm{X}^{*}\right)=\mathrm{US} \$ 675.92$, is comparable to a total willingness to pay estimate-from a CV survey-for a hypothetical conservation program that helps a tiger population grow to a steady state of $X^{*} \cong 57$ tigers, relative to a baseline where the tiger is expected to go locally extinct. This is comparable, for instance, to the total WTP estimated by the CV method in Bandara and Tisdell (2005) for a hypothetical elephant conservation program in Sri Lanka that changes the population abundance relative to its current status. The main difference in what each study measures is that they estimate the TEV (use and non-use values) while we estimate an existence value (a non-use value) that includes the values of spiritual ecosystem services derived by the Soligas tribe from the tiger.

Fewer studies measure the marginal benefits of increasing wildlife populating. Loomis and Larson (1994) used a CV survey and found that whale watching visitors are willing to pay $\$ 25.0$ and $\$ 29.7$ for $50 \%$ and $100 \%$ increase in gray whale population, respectively. In contrast, households were willing to pay $\$ 16.2$ and $\$ 18.1$ for $50 \%$ and $100 \%$ increase in the gray whale population, respectively. The authors found evidence of a diminishing marginal WTP for these two levels of population increase, which is consistent with consumer theory. In our case, marginal values of increases in the tiger population can be calculated 


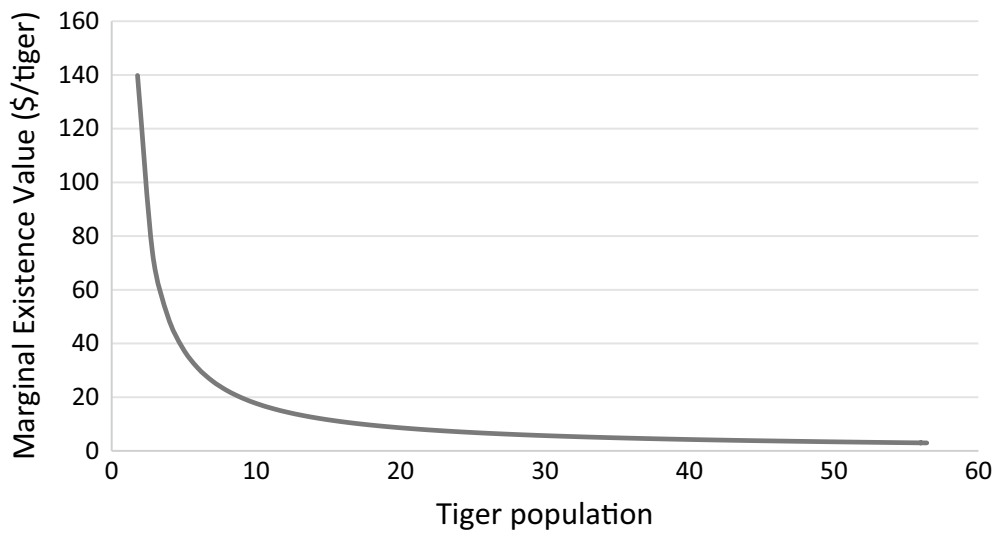

Fig. 6 Marginal existence value of the Bengal tiger in BRT (based on PS1)

using the backed-out existence parameter value to compute an existence value for two population levels. For example, in Policy Scenario 1, we find that the tribe's existence value increases by $\$ 47.8$ (from $\$ 579.9$ to $\$ 627.7$ ) if the population increases by $31 \%$ from its baseline value (from 32 to 42 tigers). Similarly, the tribe's existence value increases by $\$ 82.3$ (from $\$ 579.9$ to $\$ 662.2$ ) if the population increases by $62 \%$ (from 32 to 52 tigers). Consistently with testing that the marginal WTP estimates are diminishing in Loomis and Larson (1994), one can compute the marginal increases in existence values. We find that these are equal to $\$ 4.5 /$ tiger for a $31 \%$ increase (from 32 to 42 tigers) and diminish to $\$ 4.1$ / tiger for a $62 \%$ increase (from 32 to 52 tigers). As with the earlier example, the comparison with the whale watching study is meant to illustrate how what we learn about existence value estimates of the tiger in the BRT reserve resonates with the valuation literature in terms of the interpretation of the estimates, with the limitation that the extant literature estimates TEV (use and non-use values) or the relative importance of non-use to use values (Bandara and Tisdell 2003), whereas we obtain estimates for a specific type of non-use value-those derived from the existence of the tiger in the BRT reserve for the tribe that venerates it.

More generally, we can generate a marginal existence value curve for the tiger in the BRT reserve (Fig. 6). This marginal value function is the equivalent of a marginal WTP function from a CV study. Eiswerth and Kooten (2009) argue that such a function is more useful for policy analysis than the prevailing average and total existence value estimates, especially for species that are endangered, with low and decreasing populations.

\section{Discussion and Conclusion}

The simulation of the various conservation management scenarios in our model yields several key policy results. The policy scenario of secure property rights in the presence of a poaching penalty represents the actual BRT situation in our model simulation. The Soligas tribe have secured their property rights to the reserve in accordance with the Forest Rights Act and poaching within a protected area is penalized as per the Wildlife Protection Act. A penalty of $\$ B$ is imposed upon the harvester if she is caught by conservation authorities-with some positive probability-harvesting the resource 
illegally. In Fig. 2, with secure property rights for the Soligas and $B=\$ 769$, our model yields convergence of the stock to its steady-state equilibrium value of $X^{*}=56.55$ from the initial value of $X_{0}=35$. This policy scenario simulation backed out an existence value weight of $\beta=167.50$, which yielded an existence value of $\beta \ln \left(X^{*}\right)=\mathrm{US} \$ 675.92$ in steady-state equilibrium. The $\beta$ value derived in this scenario captures the tribe's perception of the spiritual ecosystem service of tigers in the BRT using a revealed preference approach.

Treating the actual situation in the BRT reserve as a baseline, we examined the potential outcomes under alternative policy scenarios. In the policy scenario depicted in Fig. 4, where the Soligas have secure property rights in the BRT tiger reserve but no poaching penalty exists, we observed that the stock, $X(t)$, converges to its steady-state equilibrium value of $X^{*}=56$ from the initial value of $X_{0}=35$. The corresponding existence value that we derived numerically was equal to $U S \$ 674.27$ in steady-state equilibrium. For this policy scenario, the existence value weight of $\beta=167.50$ was imposed upon it from the baseline since the tribe's perception of the spiritual ecosystem service of tigers would presumably remain unchanged, regardless of the policy scenario. The equilibrium value of $X^{*}=56$ and the existence value of $U S \$ 674.27$ are slightly lower than those under the baseline scenario; this result is contingent on the $\beta$ value that was imposed from the baseline. The expected payment of a penalty raises the stakes of harvesting the protected resource illegally, and this is demonstrated in the harvester reducing offtake in steady-state perpetuity-as listed in Table 2.

The public benefits of tiger spirituality for the Soligas are reinforced via a penalty policy for illegal harvest. However, one must keep in mind that the monitoring and enforcement involved in a penalty policy generate costs for conservation authorities. If achieving a sustainable tiger population is the principal aim of conservation policy, securing a resident tribe's property rights and consequently protecting the existence value it derives from the tiger appears to work very effectively without the need for imposing a penalty policy. Steady-state stock values in these cases correspond to the phase diagrams associated with $\phi_{2}(X, Y ; \delta)$ or $\phi_{3}(X, Y ; \delta)$ in Fig. 1 . Of course, granting and securing property rights is costly as well and depends on unpredictable court decisions and their enforcement.

Decisions that lead to taking away tribal property rights or lack of enforcement of decisions that safeguard their property rights would likely result in localized tiger extinction. In Fig. 5, we observed that when property rights are taken away from the Soligas, extinction is rendered as the outcome of our model within 38 years: a situation of insecure property rights leads the Soligas tribe to be myopic and neglect existence value that might be derived from the tiger. In Fig. 3, extinction occurs in 49 years when there is a poaching penalty present. In this case, one advantage of having a penalty policy is that localized tiger extinction takes longer to occur than in the no penalty scenario (38 vs. 49 years; Fig. 5 and Table 2). Inclusionary policies without penalty provide policymakers the advantage of securing a higher stock and safeguarding the existence values it generates while avoiding the burden of monitoring and enforcement associated with harvesting penalties.

The incentive to harvest the tiger resource for private gain would potentially increase with a higher poaching price, $p$. If the ratio of price to harvest costs were to increase such that $(p / c) \gg 1$, then resource extinction would likely be rendered optimal since $p$ would be much higher than $c$ for the last resource unit (Conrad 2010). This situation would correspond to the implicit equation $\phi_{1}(X, Y ; \delta)$ that yielded localized tiger extinction in the phase diagram of Fig. 1. One can infer that if poaching prices were to become higher over time with reductions in tiger population then, it would be especially prudent to secure the Soligas' property rights 


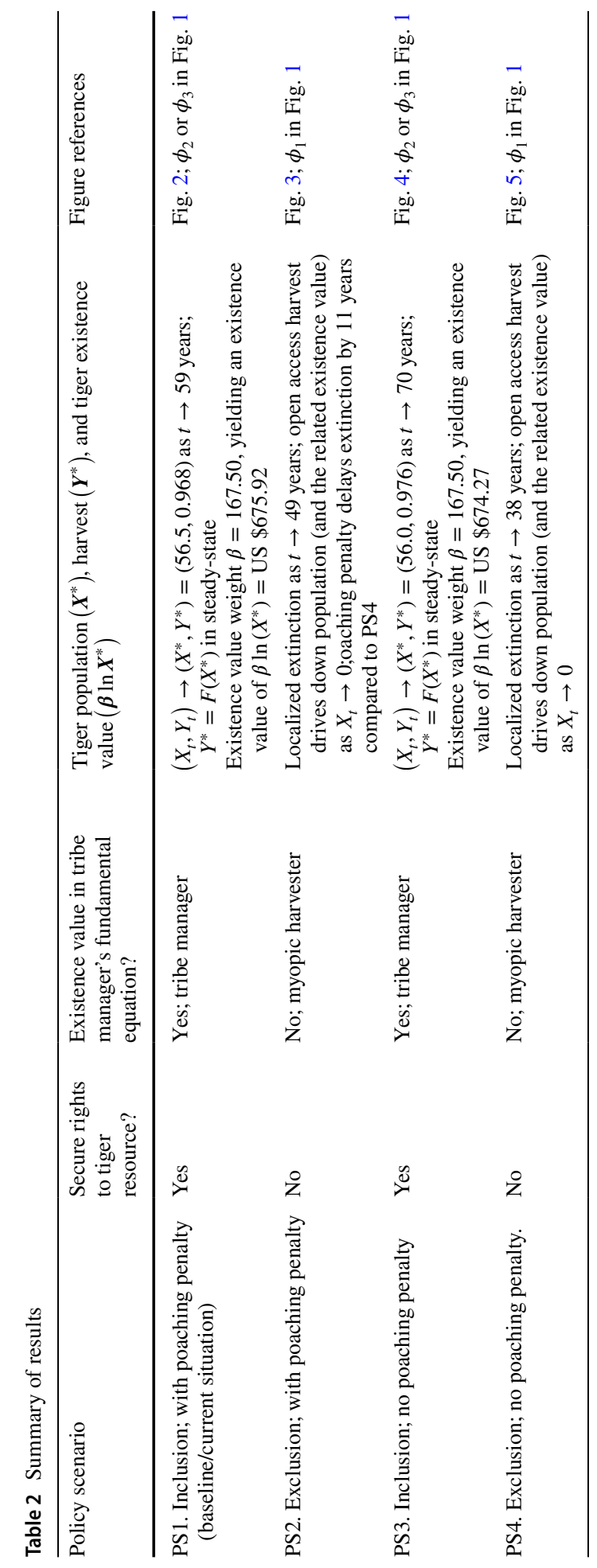


so that myopic harvesting is avoided, existence values are realized, and the tiger population is conserved.

In addition to providing a framework to test the statement that "tribal peoples are the best conservationists and guardians of the natural world", the novelty of this paper is in the nonmarket valuation of an important, but yet-to-be valued aspect of species of conservation concern: the non-use, existence value of wildlife to the tribes that co-exist with them and venerate them. So far, non-use values can only be estimated using contingent valuation and discrete choice experiment surveys. Survey-based non-market valuation approaches to estimate existence values derived by indigenous populations might not be appropriate (Adamowicz et al. 1998). Moreover, such surveys typically generate average and total WTP estimates of species preservation, without the policy-relevant information on marginal WTP and how marginal WTP changes as a function of population abundance (Eiswerth and Kooten 2009).

In the absence of functions that can be used to model tiger existence values, Zabel et al. (2011) identify ranges of such values for society. The bioeconomic model developed in this paper attempts to fill this gap by using a nonlinear specification of an existence value function and estimating existence values for a tribe that derives spiritual values from the tiger, as opposed to identifying a range of such values for society at large that typically capture moral satisfaction, "warm glow," and ethical dimensions (Alpizar et al. 2003). The simulations presented here have incorporated and backed out existence values and ascertained likely approach paths for tigers in the BRT based on the Soligas's spiritual traditions.

Our model is general enough to be applied to examine the resource dynamics of several other endangered species that provide spiritual ecosystem services-both fauna and flora. Existence values in general, and those derived from spiritual services in particular, stretch to many other species revered by native tribes and forest dwellers around the world. Securing tribal property rights as a conservation policy tool is costly, and government bodies face limited financial and human resources. Having estimates of the existence values placed by tribes in different parks through a framework like the one presented here can offer policymakers information to obtain more complete estimates of non-use values needed for ex-ante and expost natural resource damage assessments and project appraisals (Carson et al. 1992).

Such value estimates can also help policymakers efficiently allocate scarce conservation resources to parks with the highest potential for desired conservation outcomes. Of particular relevance to policy analysis, is knowing how marginal existence values might change as a function of wildlife population levels. For instance, existence values and marginal existence value functions like the ones estimated here can be used for conservation reserve site planning using tools such as the InVEST model (e.g., Polasky et al. 2011) or in conservation portfolio design models (e.g., Mallory and Ando 2014). Existence value estimates can help prioritize where policy efforts should be focused to maximize conservation return on investment, in ways that do not ignore tribal traditions and recognize the public good values they generate.

Acknowledgements The authors thank Jon Conrad and Charles Sims for their valuable feedback.

Open Access This article is licensed under a Creative Commons Attribution 4.0 International License, which permits use, sharing, adaptation, distribution and reproduction in any medium or format, as long as you give appropriate credit to the original author(s) and the source, provide a link to the Creative Commons licence, and indicate if changes were made. The images or other third party material in this article are included in the article's Creative Commons licence, unless indicated otherwise in a credit line to the material. If material is not included in the article's Creative Commons licence and your intended use is not permitted by statutory regulation or exceeds the permitted use, you will need to obtain permission directly from the copyright holder. To view a copy of this licence, visit http://creativecommons.org/licenses/by/4.0/. 


\section{References}

Adamowicz W, Beckley T, Macdonald DH, Just L, Luckert M, Murray E, Phillips W (1998) In search of forest resource values of indigenous peoples: are nonmarket valuation techniques applicable? Soc Nat Res 11(1):51-66. https://doi.org/10.1080/08941929809381061

Albers H, Ferraro P (2006) Economics of biodiversity conservation in developing countries. In: Toman MLR (ed) Economic development and environmental sustainability: new policy options. OUP, New York

Alexander RR (2000) Modelling species extinction: the case for non-consumptive values. Ecol Econ 35(2):259-269. https://doi.org/10.1016/S0921-8009(00)00198-1

Alpizar F, Carlsson F, Martinsson P (2003) Using choice experiments for non-market valuation. Econ Issues 8(1):83-110

Ando AW, Langpap C (2018) The economics of species conservation. Ann Rev Resour Econ 10(1):445467. https://doi.org/10.1146/annurev-resource-100517-022921

Bandara R, Tisdell CA (2003) Use and non-use values of wild Asian elephants. Sri Lankan Econ J 4:3-30

Bandara R, Tisdell C (2005) Changing abundance of elephants and willingness to pay for their conservation. J Environ Manage 76(1):47-59

Bhagwat S, Kushalappa C, Williams P, Brown N (2005) The role of informal protected areas in maintaining biodiversity in the Western Ghats of India. Ecol Soc 10(1):8

Bhullar L (2008) The Indian forest rights act 2006: a critical appraisal. Law Environ Develop J 4(1):394

Bulte E, Rondeau D (2007) Compensation for wildlife damages: habitat conversion, species preservation and local welfare. J Environ Econ Manag 54(3):311-322. https://doi.org/10.1016/j.jeem.2007.02.003

Bulte EH, van Kooten GC (1999a) Economics of antipoaching enforcement and the ivory trade ban. Am J Agric Econ 81(2):453-466

Bulte EH, van Kooten GC (1999b) Marginal valuation of charismatic species: implications for conservation. Environ Resour Econ 14(1):119-130

Carson RT, Mitchell RC, Hanemann WM, Kopp RJ, Presser S, Ruud PA (1992) A contingent valuation study of lost passive use values resulting from the exxon valdez oil spill. University Library of Munich, Germany

Clark CW, Munro GR, Sumaila UR (2010) Limits to the privatization of fishery resources. Land Econ 86(2):209-218

Conrad JM (2010) Resour Econ, 2nd edn. Cambridge University Press, New York

Copeland BR, Taylor MS (2009) Trade, tragedy, and the commons. Am Econ Rev 99(3):725-749

Damania R, Stringer R, Stith B (2003) The economics of protecting tiger populations: linking household behavior to poaching and prey depletion. Land Econ 79(2):198-216

Damodaran A (2007) The project tiger crisis in India: moving away from the policy and economics of selectivity. Environ Values 16(1):61-77

Davidson MD (2013) On the relation between ecosystem services, intrinsic value, existence value and economic valuation. Ecol Econ 95:171-177. https://doi.org/10.1016/j.ecolecon.2013.09.002

Desvousges WH, Johnson FR, Dunford RW, Boyle KJ, Hudson SP, Wilson KN (1992) Measuring natural resource damages with contingent valuation: anexperimental evaluation of accuracy. Research Triangle Institute, Research Triangle Park, North Carolina

Dowie M (2009) Conservation refugees: the hundred-year conflict between global conservation and native peoples. MIT Press, Cambridge

Eiswerth ME, Kooten VGC (2009) The ghost of extinction: preservation values and minimum viable population in wildlife models. Ecol Econ 68(7):2129-2136

Engel S, Pagiola S, Wunder S (2008) Designing payments for environmental services in theory and practice: an overview of the issues. Ecol Econ 65(4):663-674. https://doi.org/10.1016/j.ecolecon.2008.03.011

Fanari E (2019) Struggle for community rights in the protected areas of Biligiri Ranganatha temple (BRT), India. Retrieved from https://ejatlas.org/conflict/struggle-for-community-rights-in-the-protected-areas -of-biligiri-ranganatha-temple-brt

Fischer C, Muchapondwa E, Sterner T (2011) A bio-economic model of community incentives for wildlife management under CAMPFIRE. Environ Resour Econ 48(2):303-319

GOI (2018) India average daily wage rate: 1965-2018. Retrieved from https://tradingeconomics.com/india /wages

Hilton-Taylor C, Pollock CM, Chanson JS, Butchart SHM, Oldfield TEE, Katariya V (2009) Status of the world's species. IUCN, Gland

KFD (2017) Tiger reserves. Retrieved from http://aranya.gov.in/Static\%20Pages/TigerReserves.aspx 
Lele S, Wilshusen P, Brockington D, Seidler R, Bawa K (2010) Beyond exclusion: alternative approaches to biodiversity conservation in the developing tropics. Curr Opin Environ Sustain 2(1):94-100. https:// doi.org/10.1016/j.cosust.2010.03.006

Loomis JB, Larson DM (1994) Total economic values of increasing gray whale populations: results from a contingent valuation survey of visitors and households. Marine Resour Econ 9(3):275-286

Mallory ML, Ando AW (2014) Implementing efficient conservation portfolio design. Resour Energy Econ 38:1-18. https://doi.org/10.1016/j.reseneeco.2014.05.001

Milner-Gulland EJ, Leader-Williams N (1992) A model of incentives for the illegal exploitation of black rhinos and elephants: poaching pays in Luangwa valley, Zambia. J Appl Ecol 29(2):388-401. https:// doi.org/10.2307/2404508

MOEF (2013) The wild life (Protection) amendment act, 2013. Retrieved from New Delhi: http://www. moef.nic.in/division/wildlife

Pishro-Nik H (2014) Introduction to probability, statistics, and random processes. Kappa Research, LLC, Blue Bell

Polasky S, Nelson E, Pennington D, Johnson KA (2011) The impact of land-use change on ecosystem services, biodiversity and returns to landowners: a case study in the State of Minnesota. Environ Resour Econ 48(2):219-242. https://doi.org/10.1007/s10640-010-9407-0

Reddy CS, Yosef R (2016) Living on the edge: attitudes of rural communities toward bengal tigers (Panthera tigris) in central India. Anthrozoös 29(2):311-322. https://doi.org/10.1080/08927936.2016.1152763

Rust N (2016) There are people living in India with wild tigers. Earth. Retrieved from http://www.bbc.com/ earth/story/20160607-there-are-people-in-india-happily-living-with-wild-tigers

Sengar S (2019) More than 10 lakh forest dwellers to be homeless after supreme court orders eviction. India Times Retrieved from https://www.indiatimes.com/news/india/more-than-10-lakh-forest-dwellers-tobe-homeless-after-supreme-court-orders-eviction-362565.html

Skonhoft A (1998) Resource utilization, property rights and welfare-wildlife and the local people. Ecol Econ 26(1):67-80. https://doi.org/10.1016/S0921-8009(97)00066-9

Skonhoft A, Solstad JT (1996) Wildlife management, illegal hunting and conflicts. A bioeconomic analysis. Environ Develop Econ 1(2):165-181. https://doi.org/10.1017/s1355770x00000577

Smirnov N, Dale M (1999) Population dynamics of the Amur tiger in Sikhote-Alin Evgeny. In: Seidensticker J, Christie S, Jackson P (eds) Riding the tiger: tiger conservation in human-dominated landscapes. Cambridge University Press, Cambridge

Swanson T, Barbier E (1992) Economics for the wilds: wildlands, wildlife, diversity and development. Earthscan, London

Varma K (2015) Revealed: tiger numbers increase when tribe stays in tiger reserve. Retrieved from https:// www.survivalinternational.org/news/11004

Vipat A, Bharucha E (2014) Sacred groves: the consequence of traditional management. J Anthropol 2014:8. https://doi.org/10.1155/2014/595314

WB (2017) Consumer price index for India (2010 prices). Retrieved from Washington, DC: https://data. worldbank.org/indicator/FP.CPI.TOTL?locations=IN\&view =chart

WPSI (2010) Skinning the cat: crime and politics of the big cat skin trade. Retrieved from http://wpsi-india .org/images/EIA-WPSI_Skinning_The_Cat.pdf

WPSI (2019) Tiger poaching statistics. Retrieved from http://www.wpsi-india.org/statistics/index.php

WWF (2016) Global wild tiger population increases, but still a long way to go. News \& Stories. Retrieved from http://wwf.panda.org/wwf_news/?265197/Global-wild-tiger-population-increases-but-still -a-long-way-to-go

Zabel A, Pittel K, Bostedt G, Engel S (2009) Comparing conventional and new policy approaches for carnivore conservation - theoretical results and application to tiger conservation. Institute for Environmental Decisions, Working Paper 6. Swiss Federal Institute of Technology Zurich. Retrieved from https:// papers.ssrn.com/sol3/papers.cfm?abstract_id=1430381

Zabel A, Pittel K, Bostedt G, Engel S (2011) Comparing conventional and new policy approaches for carnivore conservation: theoretical results and application to tiger conservation. Environ Resour Econ 48(2):287-301. https://doi.org/10.1007/s10640-010-9411-4

Publisher's Note Springer Nature remains neutral with regard to jurisdictional claims in published maps and institutional affiliations. 